\title{
Sustainable Logistics Network Modeling for Enterprise Supply Chain
}

\author{
Lan Zhu and Dawei Hu \\ School of Automobile, Chang'an University, Xian, Shaanxi, China \\ Correspondence should be addressed to Lan Zhu; zhulanfighting@163.com
}

Received 9 September 2016; Revised 27 December 2016; Accepted 5 January 2017; Published 15 February 2017

Academic Editor: Rita Gamberini

Copyright ( 2017 Lan Zhu and Dawei Hu. This is an open access article distributed under the Creative Commons Attribution License, which permits unrestricted use, distribution, and reproduction in any medium, provided the original work is properly cited.

\begin{abstract}
With the expansion of the study about green logistics, sustainable supply chain management (SSCM) has appeared as a new concept in current economic circumstance. This paper studies the sustainability optimization of enterprise logistics network from a strategic perspective and proposes a multiobjective sustainable logistics optimization model considering three dimensions of sustainability: economy, environment, and society. In this model, the environment factor was measured with a Life Cycle Assessment (LCA) method based on Chinese Life Cycle Database (CLCD), while for social factors, Sustainability Reporting Guidelines (GRI) are utilized to quantify the social performance. Moreover, the model was solved with an adapted version of the $\varepsilon$-constraint method named augment constraint algorithm (AUGMENCON) through GAMS software. The numerical experiment results of a computer manufacturer supply chain show that the proposed model is able to integrate all dimensions of sustainability and simultaneously prove the capability of AUGMENCON in providing a set of trade-off solutions for the decision makers to make different decisions under different environment and social requirements.
\end{abstract}

\section{Introduction}

Sustainable supply chain management (SSCM) has been an increasingly important topic in the field of sustainability and supply chain management (SCM). Carter and Rogers [1] define SSCM as the strategic, transparent integration and achievement of an organization's social, environmental, and economic goals in the systemic coordination of key interorganizational business processes for improving the long-term economic performance of the individual company and its supply chains. Nowadays, requirements from both government and customers urge enterprises to concern environmental protection and assume more social responsibility. The sustainable development has become one of the operational rules for enterprise. Some leading enterprises, such as IKEA, HP, IBM, and GE, are all implementing "sustainable" measures to be more socially responsible and set up a good corporate image at the same time. Some scholars [2] consider SSCM as an extension of green supply chain management (GSCM) by introducing social consideration to improve enterprise management. However, existing research indicates that the integration study of society dimension with other two dimensions is not as mature as the integration study of environment dimension with economic dimension. Figure 1 shows the integration of SCM and sustainability.

This paper studies the logistics network optimization problem from the perspective of sustainability development and correspondingly proposes a multiobjective model. In the model, a Life Cycle Analysis (LCA) method on the base of Chinese Life Cycle Database (CLCD) is used in measuring the environment impact. CLCD represents the average of the Chinese market and in line with Chinese government policy, and the research based on it is limited. As far as we know, this is the first literature that implements the CLCD database into the network optimizing problem. Regarding society dimension, Sustainability Reporting Guidelines (GRI) are utilized to quantify the social performance in four aspects. The proposed model is used for designing a computer manufacturer supply chain as a case study which can prove the practical value of this research. In addition, AUGMENCON algorithm (an adaptive version of $\varepsilon$-constraint method) is implemented to solve the multiobjective model. 


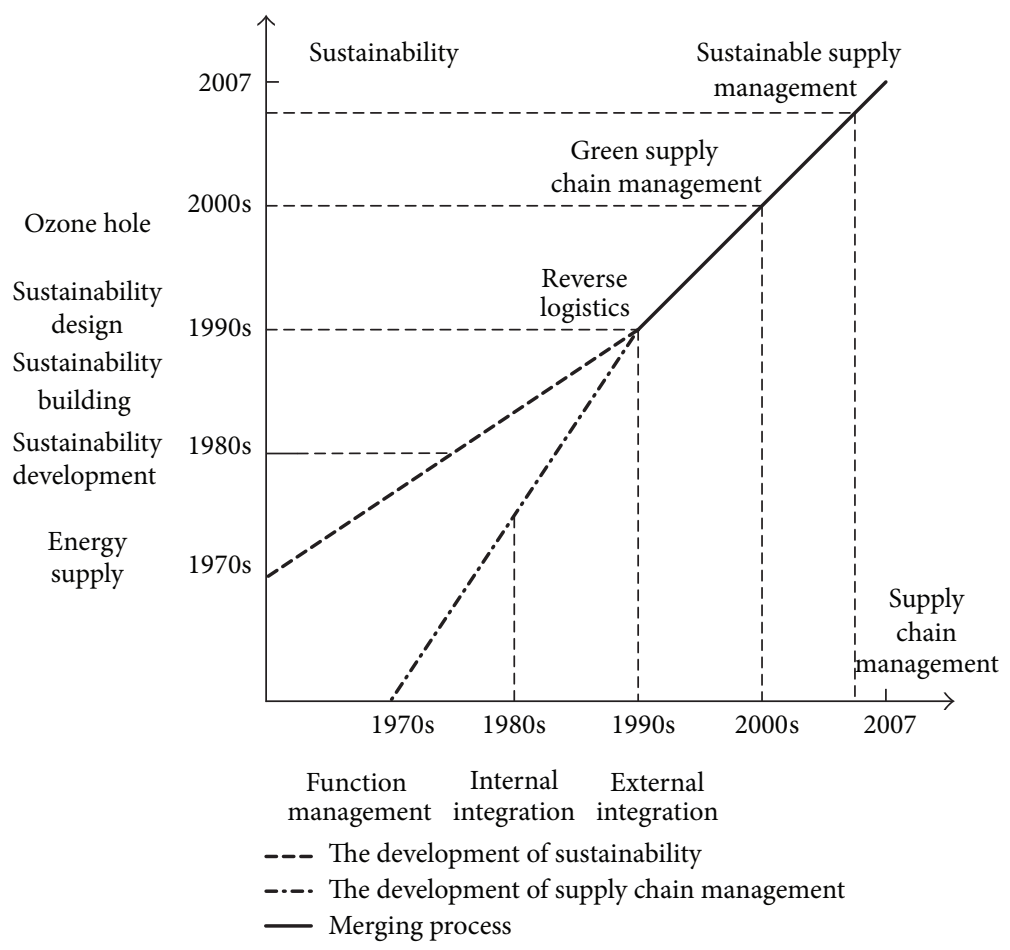

FIGURE 1: Merging process of sustainability and SCM.

The rest of the paper is organized as follows. In the second section, the literature review is presented. In Section 3, the proposed model is characterized. Section 4 introduces the multiobjective optimization algorithm used in this paper. Section 5 describes a case study, and the experiment results are discussed. Finally, conclusions are drawn in Section 6, and future work directions are also discussed.

\section{Literature Review}

\subsection{Measurement of Sustainability Dimensions}

2.1.1. Economic Dimension. The general measurement of the economic factor is based on the calculation of total network cost or net profit. Total network cost usually includes facility establishment cost, transportation cost, inventory cost, and production cost. Different supply chain structures correspond to different cost composition, as studied in the literature [3-5]. Wang et al. [6] consider investment cost of environment protection as a part of network cost. Chaabane et al. [7] introduce carbon credit cost into cost factor. Pishvaee et al. [8] consider the cost savings from establishing multifunctional facility compared with the monofunctional facility.

2.1.2. Environment Dimension. The measurement of environment factor usually bases on $\mathrm{CO}_{2}$ emission or $\mathrm{CO}_{2}$ equivalent emission. The Intergovernmental Panel on Climate Change (IPCC) proposed method and carbon footprint method are typical approaches. Cholette and Venkat [9] study a wine supply chain and calculate the energy consumption and $\mathrm{CO}_{2}$ emission from inventory and transportation through Cargo Scope software. Edwards et al. [10] compare the carbon emission intensity between "last mile" distribution and traditional distribution. Xiao et al. [11] propose suggestions about energy conservation to logistical process from the perspective of carbon emission, energy consumption, carbon intensity, and energy intensity. Besides, some emerging concepts are gradually introduced into the measurement of supply chain performance, such as emission trading scheme [6], carbon $\operatorname{tax}[12]$, and green reputation [13]. Furthermore, other GHG emissions $\left(\mathrm{NO}_{X}, \mathrm{SO}_{2}\right.$, and $\left.\mathrm{CO}\right)$, energy consumption (water, electricity, fuel oil, and land), and waste discharge are studied to measure the environment impact. Ferretti et al. [14] study the environment impact of $\mathrm{NO}_{X}, \mathrm{PM}, \mathrm{CO}$, and VOCs emission in remelting process of the aluminum supply chain.

Life Cycle Assessment (LCA) is a method that measures the environmental load caused by a certain product or process during its entire lifecycle from production, transportation, usage to discard, and reproduction. Pizzol et al. [15] summarize the present LCA-based environmental load assessment methods. They are CML2001 [16], Eco-indicator 99 [17], EDIP 2003 [18], EPS 2000 [19], IMPACT 2002+ [20], Ecological Scarcity [21], TRACI [22], and ReCiPe2008 [23]. In most of these methods, the environmental impact is reflected in two aspects: mid-point impact and end-point impact. To quantify and normalize the evaluation results, weighting and normalization mechanisms are available in some of these methods. These methods are implemented based on EcoInvent Database or European Reference Life Cycle Database (ELCD), while the research based on Chinese Life Cycle Database is limited. 
2.1.3. Society Dimension. Being associated with multistakeholder and multidiscipline, the measurement of social performance is always difficult to describe exactly due to high level of complexity. Therefore, research in this area is limited and has not yet formed a specialized system. The Guidance on Social Responsibility ISO-26000 [24], proposed by International Organization for Standardization (ISO), serves as guidelines for social performance measurement. ISO26000 classifies social issue into seven aspects: labor practice, customer issues, organization governance, human rights, fair operating, environment, and community development. Some credible and popular measurement methods for social performance include SA8000 [25], ETI [26], FLA [27], GC [28], GSLCAP [29], and GRI [30]. The above seven aspects are partially or fully covered to get the comprehensive social score.

Tayyar et al. [31] study the sustainable closed-loop supply chain design problem and minimize social satisfaction. Chen and Andresen [32] choose the number of occupational injury as the social indicator in social performance measurement. $\mathrm{Xu}$ and Teng [33] study a multiobjective sustainable closedloop supply chain design problem, and the social indicator is composed of created job opportunity, annual lost days, potentially hazardous, and charity development. On selecting social indicators, the above-mentioned papers are deficient in universality due to the lack of clear theory system.

2.2. Integration of the Three Dimensions. The integration of all three dimensions is critical to the final decisionmaking process, and its application always involves several topics such as reverse logistic network, recycling and waste management, manufacture, and remanufacture. For instance, Gamberini et al. conduct a significant amount of research on the topic of sustainable waste management. They study the network design problem of electric and electronic equipment recovery [34] and technical solutions problem for collection and transport [35]. They also study the municipal solid waste management (MSWM) problem and introduce the definition and utilization of engineering indexes [36] in this area and make an empirical analysis of existing plants [37].

As for the modeling approaches, they can be grouped into four categories [38]: multicriteria decision-making (MCDM), equilibrium models, models based on LCA, and analytical hierarchy process (AHP). MCDM is a powerful tool for coping with trade-offs among conflicting objectives regarding both criteria and decision makers. Lolli et al. [39] introduce a MCDM method called fuzzy PROMETHEE approach that combines the traditional environmental criteria of LCA with social and economic criteria to solve the best waste treatment solution selection problem. Yang et al. [40] propose a multiobjective programming model to balance the equilibrium among emission, production, trading volume, and trading price. Compared with three above-mentioned quantitative methods, AHP can provide a qualitative and the quantitative decision-making mechanism when dealing with complex supply chain decisions, as literature [41, 42] shows.

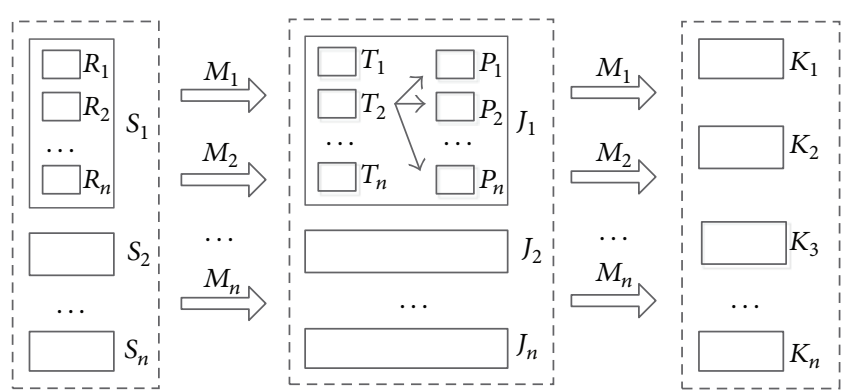
S: supplier
$J$ : plant
$K$ : customer
$R$ : raw material
$P$ : product
$T$ : technology
$M$ : transportation mode

FIGURE 2: Structure of constructed supply chain.

\section{Problem Formulations}

3.1. Supply Chain Structure. The three-level supply chain constructed in this paper includes supplier, manufacturing plant, and customer. The aim is to optimize the supply chain decision procedures that include facility location, technology selection, product manufacture, and demand allocation on the base of balancing the economic cost, environment impact, and social performance. The supply chain structure is shown in Figure 2.

3.2. Measurement of Environment Impact. A LCA method based on CLCD is used in this paper to measure the environment impact. Typical LCA follows the following steps.

Step 1. Calculation of life cycle inventory.

Step 2. Calculation of characteristic indicator.

Step 3. Normalization.

Step 4. Weighting.

Step 5. Calculation of weighted sum score.

Currently, CLCD is the only public available local LCA database in China. The data in it represents the average of China market. CLCD provides the normalization schemes, weighting approaches, and goal setting based on Chinese national energy conservation policies. The data recording of CLCD is realized through e-Balance software.

In this paper, $\mathrm{CN}-2010$ based normalization scheme and "Aggregative Indicators of Energy Saving and Emission Reduction in 12th Five-Year Plan" based weighting approach are selected. And the following seven characteristic indicators are chosen as environmental impact categories: primary energy consumption (PED), carbon dioxide $\left(\mathrm{CO}_{2}\right)$, industrial water use (IWU), ammonia nitrogen $\left(\mathrm{NH}_{3}-\mathrm{N}\right)$, nitric oxide $\left(\mathrm{NO}_{X}\right)$, chemical oxygen demand (COD), and sulfur dioxide $\left(\mathrm{SO}_{2}\right)$. Then we obtain an inventory list of the abovementioned impact factors and their corresponding quantities $\left(\mathrm{Val}_{l}\right)$, based on which the environmental impacts $\left(C_{m}\right)$ 
on impact category $m$ are determined. The characterization factors $\left(\alpha_{l}\right)$ in (1) are the ones from CLCD. Equation (2) shows that the normalized impact value of each impact category (Nor $\left.{ }_{m}\right)$ equals the ratio of environmental impact $\left(C_{m}\right)$ and normalization benchmark $\left(\mathrm{Nob}_{m}\right)$, where $\mathrm{Nob}_{m}$ could be derived from CLCD. Then, the aggregate environment impact equals the weighted sum of normalized impact value of each impact category (Nor ${ }_{m}$ ) as shown in (3), where $A_{m}$ represents the supplement parameter.

$$
\begin{aligned}
C_{m} & =\sum_{l} \partial_{l} \operatorname{Val}_{l} \\
\operatorname{Nor}_{m} & =\frac{C_{m}}{\operatorname{Nob}_{m}} \\
W & =\sum_{m} \eta_{m} \operatorname{Nor}_{m} A_{m} .
\end{aligned}
$$

3.3. Measurement of Social Performance. In this paper, Sustainability Reporting Guidelines (GRI) are utilized to measure the social performance. GRI is an information disclosure rule proposed by Global Reporting Initiative in 2000. It is now generally utilized by enterprises for reporting their sustainable initiatives and supervising their sustainable issues. The society dimension falls into four main categories in this guideline. They are labor practices and decent work, human rights, local society, and product responsibility. Within each main category, several subcategories are depicted, and four of them are selected as our social performance indicators. They are employment, local development, health and safety of employee, and customer risk.

The "employment" indicator relates to the plant location and technology selection decisions, and this indicator could be illustrated by "the number of jobs created" multiplied by the "regional unemployment rate" [8], which means the regions with higher regional unemployment rate need more jobs. The "local development" indicator relates to plant location decision. OECD [43] describe this indicator by "the total economic value generated by products" multiplied by "local development rate," which guarantee the balanced development among regions. The "health and safety of employee" indicator relates to technology selection decision, and "average annual lost days" [44] is applied as the indicator. The "customer risk" indicator relates to technology selection and production decisions because they concern directly the product quality. To measure this impact, we choose "the average percentage of risky products" proposed by Krajnc and Glavič [45] as the indicator.

All the data mentioned above are available and easy to collect. For example, the regional data such as "unemployment" and "local development rate" are annually provided by governmental organizations. Besides, the company relevant data such as "average annual lost days" and "the total economic value generated by products" are accessible from companies.

Because GRI itself does not provide normalization method, we chose the one employed by HDR [46] to calculate the normalized social score, as shown in (4), where $S^{\text {nor }}$ represents the normalized value of social performance and
$S, S_{\max }$, and $S_{\min }$ stand for the actual value and maximum possible and minimum possible value of social performance, respectively. Finally, an AHP-based approach utilized by Chandran et al. [47] is referred in this paper to determine the importance weight of the four indicators.

$$
\begin{aligned}
& S^{\text {nor }}=\frac{S-S_{\min }}{S_{\max }-S_{\min }} \\
& S^{\text {nor }}=\frac{S_{\max }-S}{S_{\max }-S_{\min }} .
\end{aligned}
$$

\section{Model Formulations}

See Notations.

Objectives are

$$
\begin{aligned}
& \min \cos t=\sum_{j \in J} \sum_{t \in T} \mathrm{cf}_{j} Y_{j}^{t}+\sum_{i \in I} \sum_{j \in J} \sum_{r \in R} \mathrm{cb}_{i}^{r} X_{i j}^{r} \\
& +\sum_{j \in J} \sum_{t \in T} \sum_{p \in P} \mathrm{cp}_{j}^{t p} G_{j}^{t p}+\sum_{i \in I} \sum_{j \in J} \sum_{r \in R} \mathrm{ct}^{r} X_{i j}^{r} d_{i j} \\
& +\sum_{i \in I} \sum_{j \in J} \sum_{p \in P} \mathrm{ct}^{p} X_{j k}^{p} d_{j k} \\
& \min \mathrm{EnI}=\sum_{m} \eta_{m}\left(\mathrm{PI}_{m}+\mathrm{TI}_{m}\right) \\
& =\sum_{m} \eta_{m}\left(\left(\sum_{j \in J} \sum_{t \in T} \sum_{p \in P} \operatorname{Nor} p_{m}^{p} G_{j}^{t p}\right)\right. \\
& \left.+\sum_{v \in V} \operatorname{Nor} v_{m}^{v}\left(\sum_{i \in I} \sum_{j \in J} \alpha_{i j}^{r v} Q_{v} d_{i j}+\sum_{i \in I} \sum_{j \in J} \beta_{j k}^{p v} Q_{\nu} d_{j k}\right)\right) \\
& \max \operatorname{SoI}=\omega_{1} S_{1}^{\text {nor }}+\omega_{2} S_{2}^{\text {nor }}-\omega_{3} S_{3}^{\text {nor }}-\omega_{4} S_{4}^{\text {nor }}=\omega_{1} \\
& \cdot \frac{\sum_{j \in J} \sum_{t \in T} \mathrm{jc}_{j} \mathrm{up}_{j} Y_{j}^{t}-S_{1}^{\min }}{S_{1}^{\max }-S_{1}^{\min }}+\omega_{2} \\
& \frac{\sum_{j \in J} \sum_{t \in T} \mathrm{vp}_{j}\left(1-\mathrm{edp}_{j}\right) Y_{j}^{t}-S_{2}^{\min }}{S_{2}^{\max }-S_{2}^{\min }}+\omega_{3} \\
& \frac{S_{3}^{\max }-\sum_{j \in J} \sum_{t \in T} \operatorname{ld}^{t} Y_{j}^{t}}{S_{3}^{\max }-S_{3}^{\min }}+\omega_{4} \\
& \frac{S_{4}^{\max }-\sum_{j \in J} \sum_{t \in T} \sum_{p \in P} \operatorname{pr}^{t} G_{j}^{t p}}{S_{4}^{\max }-S_{4}^{\min }} \text {. }
\end{aligned}
$$

Constraints are

$$
\begin{gathered}
\sum_{t \in T} Y_{j}^{t} \leq 1 \quad \forall j \in J \\
\sum_{j \in J} X_{j k}^{p} \geq D_{k}^{p} \quad \forall k \in K, p \in P \\
\sum_{i \in I} X_{i j}^{r}-u_{p}^{r} \sum_{t \in T} G_{j}^{t p}
\end{gathered}
$$




$$
\begin{aligned}
& \sum_{t \in T} G_{j}^{t p}-\sum_{k \in K} X_{j k}^{p}=0 \quad \forall p \in P, j \in J \\
& \sum_{t \in T} \sum_{p \in P} G_{j}^{t p}-\sum_{t \in T} \operatorname{cap}_{j} Y_{j}^{t} \leq 0 \quad \forall j \in J \\
& \alpha_{i j}^{r v}=\left\lceil\frac{\left(\sum_{r \in R} X_{i j}^{r}\right)}{\operatorname{cap}_{v}}\right\rceil \\
& \forall i \in I, \quad j \in J, \quad v \in V \\
& \beta_{j k}^{p v}=\left\lceil\frac{\left(\sum_{p \in P} Z_{j k}^{p}\right)}{\operatorname{cap}_{v}}\right\rceil \\
& j \in J, \quad \forall k \in K, v \in V \\
& Y_{j}^{t} \in\{0,1\} \quad \forall j \in J, t \in T \\
& X_{j k}^{p}, Z_{j k}^{p}, G_{j}^{t p} \geq 0 \quad \forall j \in J, t \in T, p \in P .
\end{aligned}
$$

Equation (5) is the economical objective that minimizes the total network cost which includes raw material purchase cost, production cost, and transportation cost for raw material and product. Equation (6) is the environmental objective that minimizes the total environment impact from production and transportation. Equation (7) is the social objective represented by the normalized weighting sum of four indicators. Constraint (8) restricts that a plant owns only one kind of product technology. Constraint (9) ensures that the customer demand satisfied. Constraint (10) is the correspondence between raw materials and products. Constraint (11) balances the production and consumption of the products. Constraint (12) is the capacity constraint of the plants. Equations (13) and (14) define the number of the vehicle in transportation. Equations (15) and (16) are binary and nonnegative constraints, respectively.

\section{Multiobjective Optimization}

To obtain the trade-off solutions among all dimensions of sustainability, a multiobjective optimization algorithm named augmented constraint method (AUGMENCON) [48] is used to solve the proposed model. AUGMENCON is a constraint method evolved from the traditional $\varepsilon$-constraint method by involving several improvement strategies.

5.1. Traditional $\varepsilon$-Constraint Method. Assume that the following equation (17) describes our multiobjective model. In the equation, $x$ is the vector of decision variables, and $X$ represents the feasible region. The economical objective, environmental objective, and social objective are represented by $f_{1}(x), f_{2}(x)$, and $f_{3}(x)$, respectively.

$$
\min \left(f_{1}(x), f_{2}(x)\right) \wedge \max f_{3}(x) \quad x \in X .
$$

In the $\varepsilon$-constraint method, the objective with higher priority is considered as the objective function while others are written as constraints by using constraint vector $\varepsilon$. Here, the economical objective is chosen to be optimized. Then, the model is transformed to equation (18), where $k=0, \ldots, n$ and $\Delta \varepsilon_{i}=\left(f_{i}^{\max }(x)-f_{i}^{\min }(x)\right) / n, i=2,3 \cdot r_{i}=f_{i}^{\max }(x)-f_{i}^{\min }(x)$ denotes the range of objectives.

$$
\begin{array}{ll}
\min & f_{1}(x) \\
\text { s.t. } & f_{2}(x) \leq f_{2}^{\min }(x)+k \Delta \varepsilon_{2}, \\
& f_{3}(x) \geq f_{3}^{\min }(x)+k \Delta \varepsilon_{3} \\
& x \in X .
\end{array}
$$

Although it has demonstrated the effectiveness in solving the multiobjective problem, there are still two notably weak points in $\varepsilon$-constraint method. The first one is the difficulty in obtaining objective range (mainly worst values) which is necessary for implementing the $\varepsilon$-constraint method. The other weak point lies at the guarantee of solution efficiency. Ehrgott and Wiecek [49] prove that the optimal solution of problem (18) is guaranteed to be an efficient solution only if both the two objectives' constraints are binding; otherwise, the obtained optimal solution is weakly efficient. In this regard, AUGMENCON improves the original algorithm from the following aspects.

\subsection{Improvement in AUGMENCON}

5.2.1. Lexicographic Optimization to Obtain Objective Range. Lexicographic optimization is introduced to obtain the upper bound $f_{i}^{\max }(x)$ and lower bound $f_{i}^{\min }(x)$ of each objective (take minimization problem, for instance). Regarding the difficulty in obtaining the worst values of the objective functions, reservation value scheme which acts as a lower bound is introduced, which is to say, values worse than it are excluded. Practically, the adoption progress of lexicographic optimization is described below. First, we optimize the objective with higher priority and get the optimal value $f_{1}=z_{1}^{*}$. Then next objective could be optimized with the constraint $f_{1}=z_{1}^{*}$, and the corresponding optimal $f_{2}=z_{2}^{*}$ is obtained, and so on, until all the objectives are traversed. Finally, the ranges of the objectives $f_{i}^{\max }(x)-f_{i}^{\min }(x)$ are obtained and equally divided into $n$ intervals, and thus $n+1$ grid points $g_{i}$ are obtained as the values of the right-hand side of the constraints in (18); that is, $f_{i}^{\min }(x)+k \Delta \varepsilon_{i}$.

5.2.2. Linear Relaxation to Guarantee Efficient Solutions. To avoid weakly Pareto optimal solutions, the inequality objective constraints in equation (18) are transformed to equality constraints by adding slack variables $\left(s_{2}\right.$ and $\left.s_{3}\right)$. Then the surplus variables are penalized in the objective function in the form of $s_{i} / r_{i}$ to avoid any scaling problems. Then model (18) becomes

$$
\begin{array}{ll}
\min & \left(f_{1}(x)+\operatorname{eps}\left(\frac{s_{2}}{r_{2}}+\frac{s_{3}}{r_{3}}\right)\right) \\
\text { s.t. } & f_{2}(x)+s_{2}=f_{2}^{\min }(x)+k \Delta \varepsilon_{2} \text {, }
\end{array}
$$




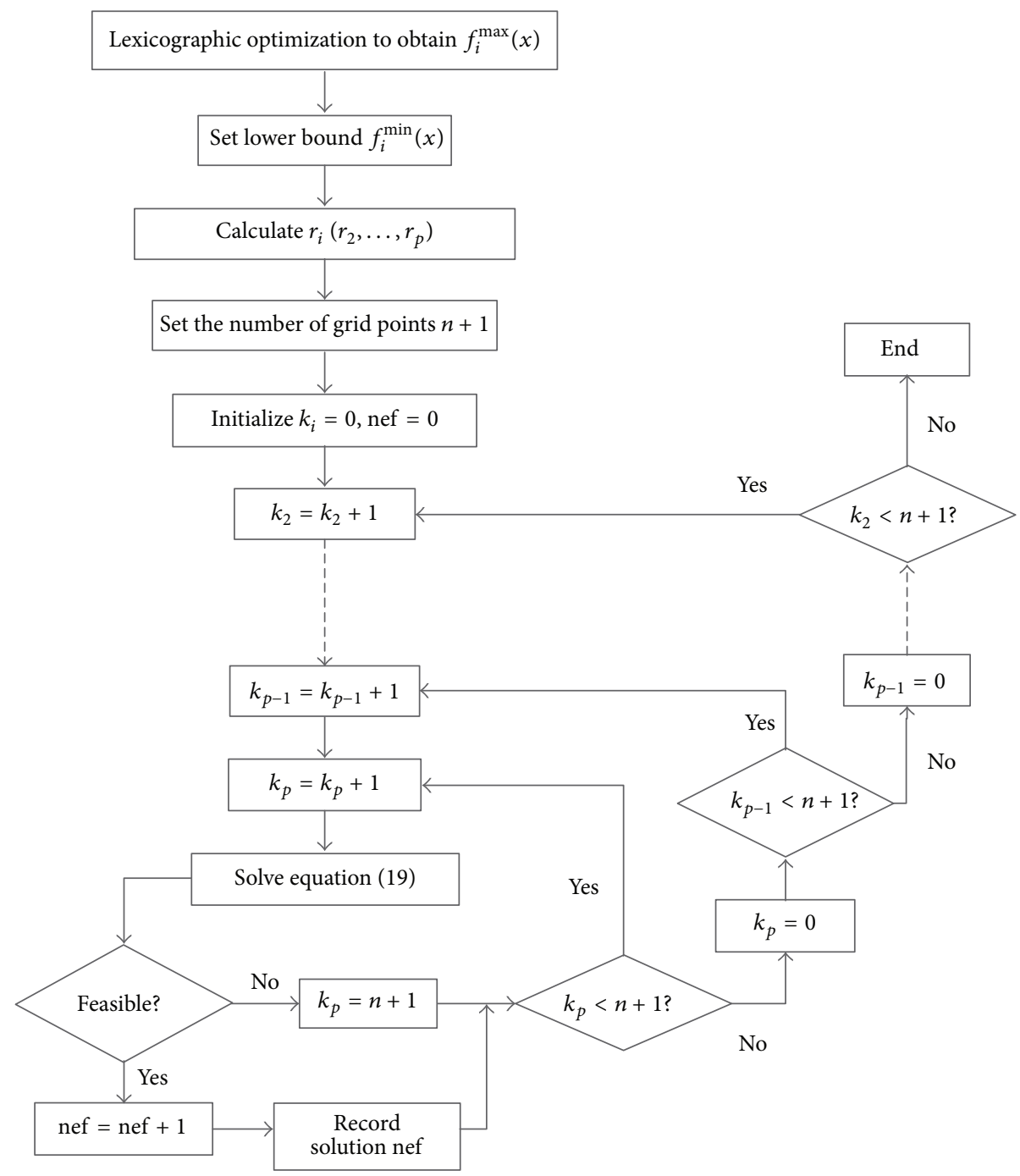

FIGURE 3: Flowchart of AUGMENCON.

$f_{3}(x)-s_{3}=f_{3}^{\min }(x)+k \Delta \varepsilon_{3}$,

$x \in X, s_{i} \in R^{+}$.

In the model, eps is a real number small enough so that the objective function is not affected. The formulation (19) avoids the ambiguity of original $\varepsilon$-constraint method and produces only efficient solutions, which is proved in the paper [48].

5.2.3. Acceleration of the Algorithm. Moreover, acceleration strategy is introduced in AUMENCON method compared with $\varepsilon$-constraint method. The algorithm begins with an objective constraint with the maximum slack and restricts it gradually. This ranking scheme ensures that the stricter objective constraints are no longer necessary, as it will also result in infeasible solutions. This means the algorithm exits from the innermost loop and continues with the next grid point. In this way, the searching efficiency is improved significantly.

The algorithm flowchart is shown in Figure 3.

\section{Implementation and Evaluation}

6.1. Case Design. To implement the proposed model and algorithm, a case of a manufacturing enterprise is constructed. The supply chain of notebook manufacturer is selected because its inventory list data of environmental impact is comparatively complete in CLCD database. Assume that a notebook manufacturer is to locate its plant nation widely, and now there are 8 potential locations with 3 types of technology for selection. It needs 3 kinds of raw material supplied by 3 different suppliers to produce 1 certain notebook. 2 kinds of transportation modes are available for two-stage transportation. Transportation from supplier to plant uses $10 \mathrm{t}$ heavy diesel truck and transportation from plant to customer uses $8 \mathrm{t}$ medium diesel truck. 
TABLE 1: Environmental impact.

\begin{tabular}{|c|c|c|c|c|c|c|c|c|}
\hline \multirow{2}{*}{$\begin{array}{l}\text { Impact } \\
\text { category }\end{array}$} & \multirow[t]{2}{*}{ Unit } & \multirow[t]{2}{*}{$\eta_{m}$} & \multicolumn{2}{|c|}{ Production (per item) } & \multicolumn{2}{|c|}{$\begin{array}{l}\text { Transportation } 1 \\
\quad(\text { per } t * \mathrm{~km})\end{array}$} & \multicolumn{2}{|c|}{$\begin{array}{l}\text { Transportation } 2 \\
\quad(\text { per } t * \mathrm{~km})\end{array}$} \\
\hline & & & $\operatorname{Nor}_{m}^{p}$ & $C_{m}$ & Nor $_{m}^{v}$ & $C_{m}$ & Nor $_{m}^{v}$ & $C_{m}$ \\
\hline PED & MJ & 6.25 & $5.889 E-09$ & $4.410 E-08$ & $6.223 E-13$ & $4.660 E-12$ & $6.920 E-13$ & $5.182 E-12$ \\
\hline $\mathrm{COD}$ & $\mathrm{kg}$ & 2.907 & $4.384 E-10$ & $5.427 E-10$ & $2.556 E-14$ & $3.164 E-14$ & $2.844 E-14$ & $3.521 E-14$ \\
\hline $\mathrm{SO}_{2}$ & $\mathrm{~kg}$ & 2.907 & $5.357 E-11$ & $1.170 E-10$ & $9.101 E-15$ & $1.989 E-14$ & $1.012 E-14$ & $2.210 E-14$ \\
\hline NH3-N & $\mathrm{kg}$ & 2.791 & $3.117 E-12$ & $3.584 E-13$ & $6.616 E-15$ & $7.608 E-16$ & $7.347 E-15$ & $8.449 E-16$ \\
\hline $\mathrm{No}_{x}$ & $\mathrm{~kg}$ & 2.791 & $3.573 E-11$ & $7.431 E-11$ & $1.766 E-15$ & $3.673 E-15$ & $3.441 E-14$ & $7.157 E-14$ \\
\hline $\mathrm{CO}_{2}$ & $\mathrm{~kg}$ & 5.882 & $3.100 E-11$ & $2.574 E-08$ & $1.937 E-14$ & $1.608 E-11$ & $1.782 E-14$ & $1.480 E-11$ \\
\hline IWU & $\mathrm{kg}$ & 3.333 & $3.701 E-11$ & $5.340 E-07$ & $7.475 E-16$ & $1.079 E-11$ & $9.918 E-16$ & $1.431 E-11$ \\
\hline
\end{tabular}

TABLE 2: Plant relevant social parameters.

\begin{tabular}{lcccccccc}
\hline Plant & 1 & 2 & 3 & 4 & 5 & 6 & 3 & 35 \\
\hline $\mathrm{jc}_{j}$ & 37 & 38 & 36 & 35 & 33 & 39 & 3.3 & 3.5 \\
up $_{j}$ & 3.3 & 3.3 & 3.6 & 3.2 & 120 & 165 & 150 & 120 \\
$\mathrm{vp}_{j}$ & 150 & 158 & 120 & 0.112 & 0.111 & 0.100 & 0.111 & 0.099 \\
$\mathrm{edp}_{j}$ & 0.097 & 0.111 & 0.112 & 0.097 \\
\hline
\end{tabular}

TABLE 3: Technology relevant parameters.

\begin{tabular}{lccc}
\hline Technology & 1 & 2 & 3 \\
\hline $\mathrm{ld}^{t}$ & 17 & 24 & 13 \\
$\mathrm{pr}^{t}$ & 0.002 & 0.001 & 0.003 \\
\hline
\end{tabular}

6.2. Parameter Setting. Regarding environmental indicators, 7 environment impact categories are selected as Table 1 shows, and the categories with higher impact level are highlighted in italic. The LCA procedure is performed in eBalance software.

In terms of social indicators, regional data is collected from national bureau of statistics website and the company relevant data refers to [33], as shown in Tables 2 and 3.

6.3. Numerical Experiments. Four different scenarios are designed in this paper to carry out the numerical experiments. They are scenario A1: an optimal solution, obtained when minimizing cost; scenario A2: an optimal solution, obtained when minimizing environment impact; scenario A3: an optimal solution, obtained when maximizing social performance; scenario B: Pareto solutions, obtained when considering all objectives.

Scenario A is solved though Cplex Studio 12.5 software, and scenario B is solved by AUGMENCON method through GAMS software. Table 4 shows the location and production decision results of different scenarios. Figure 4 shows the Pareto front of feasible solutions of scenario B.

Figure 5(a) shows the total cost of the different scenarios and their composition ratio. It indicates that lower environment impact comes with higher cost (A2). In addition,

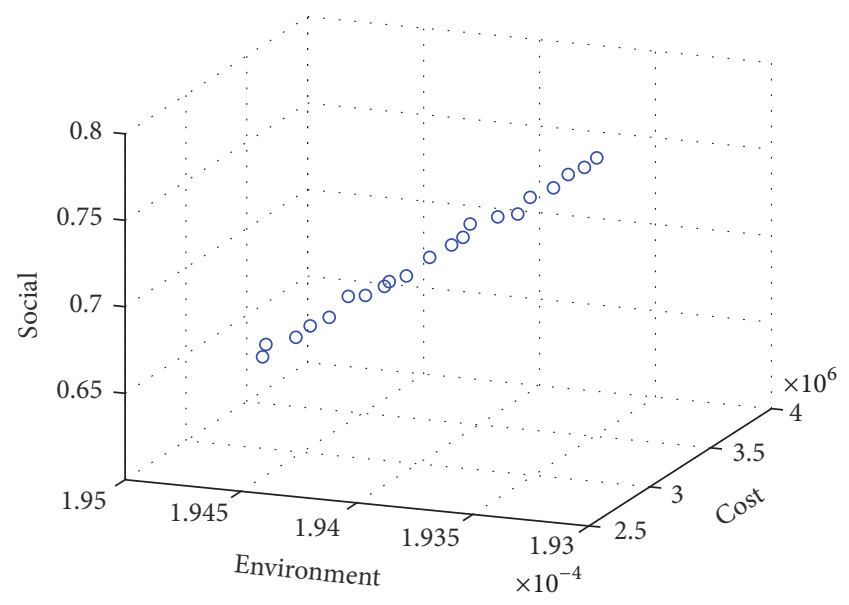

FIGURE 4: Pareto front of scenario B.

scenario A3 indicates that higher social performance corresponds to higher cost. On the one hand, it is because opening more plant provides more employment opportunities $\left(S_{1}\right)$. On the other hand, the regions with lower development level own higher probability to be chosen as location (set in term $S_{2}$ ), which leads to the selection of more remote regions, and the transportation distance increases accordingly.

In the environment aspect, as shown in Figure 5(b), social performance optimization leads to more traveled distance. Hence, the environment impact from transportation increases obviously in scenario A3. In addition, as shown in Table 4, primary energy consumption (PED), chemical oxygen demand (COD), and carbon dioxide $\left(\mathrm{CO}_{2}\right)$ are the categories with higher impact level. 
TABLE 4: Location and production decisions results.

\begin{tabular}{lcc}
\hline Scenario & Number of locations $/ \sum_{j \in J} Y_{j}^{t}$ & Production (technology used) $/ G_{j}^{t p}$ \\
\hline A1 & 3 & $1650(2)+1500(1)+1600(3)$ \\
A2 & 5 & $1500(1)+800(1)+1050(1)+600(1)+800(1)$ \\
A3 & 4 & $1520(2)+800(2)+1650(2)+780(1)$ \\
B & 3 & $1600(2)+1550(1)+1600(3)$ \\
\hline
\end{tabular}

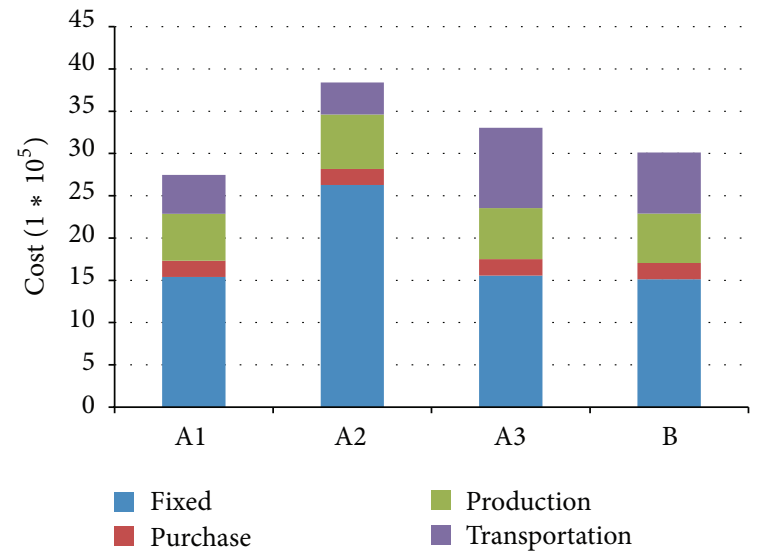

(a)

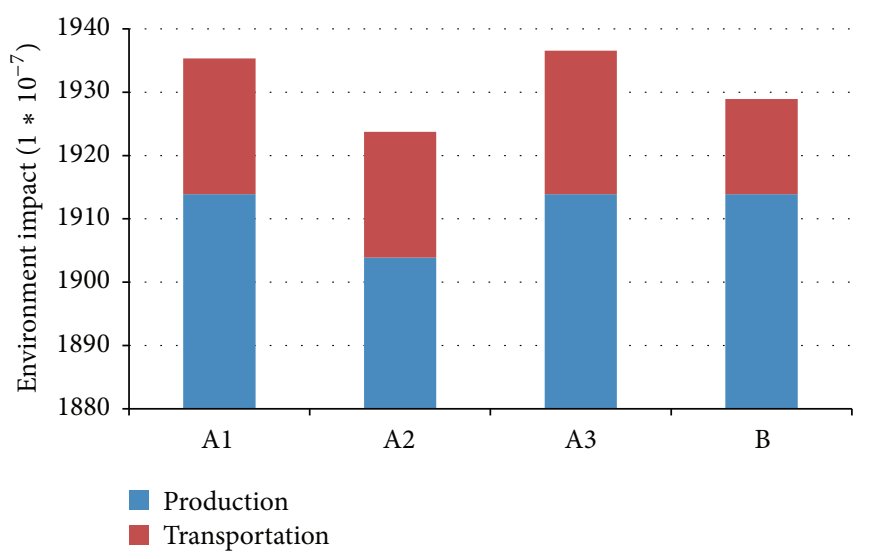

(b)

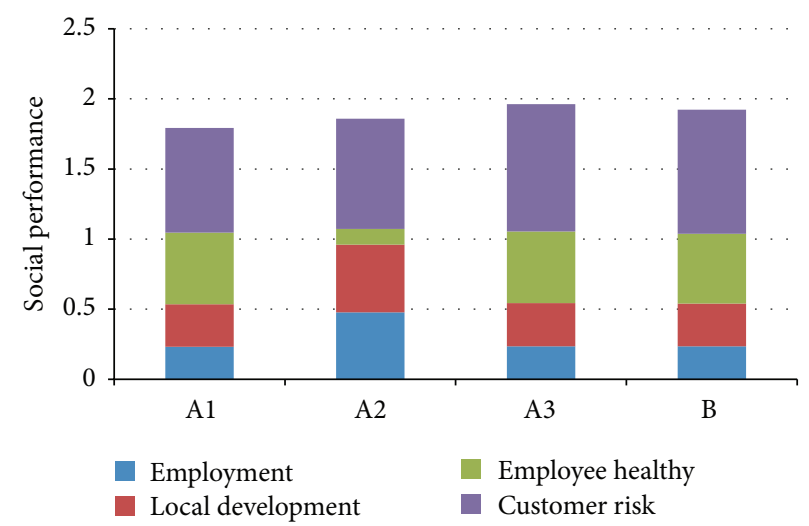

(c)

FIgURE 5: (a) Costs distribution of scenarios. (b) Environment distribution of scenarios. (c) Social performance distribution.

Social performance results in Figure 5(c) show that the term "employment" $\left(S_{1}\right)$ and "local development" $\left(S_{2}\right)$ are positively associated with the opening of plants, while the term "health and safety of employee" $\left(S_{3}\right)$ and "customer risk" relate to parameter setting.

In AUGMECON method, the number of equal intervals $n$ between the lower and upper bounds of objective values is an important parameter that influence calculation speed and accuracy markedly. The sensitivity analysis of average solution gaps in Figure 6 shows the tendency of gaps and iterations with the variation of $n$ from 2 to 10 . We can see that, under the circumstance that the iterations are almost constant, average gaps decrease a lot with the increase of $n$, which means that the solution accuracy increases.

\section{Conclusion}

In this paper, the sustainability optimization of enterprise logistics network is studied from the strategic perspective, and we mainly solved the following problems:

(i) A multiobjective optimization model for logistics network considering three dimensions of sustainability is proposed.

(ii) The measurement of environment impact is realized through an LCA method based on Chinese Life Cycle Database (CLCD), which is implemented through eBalance software. 


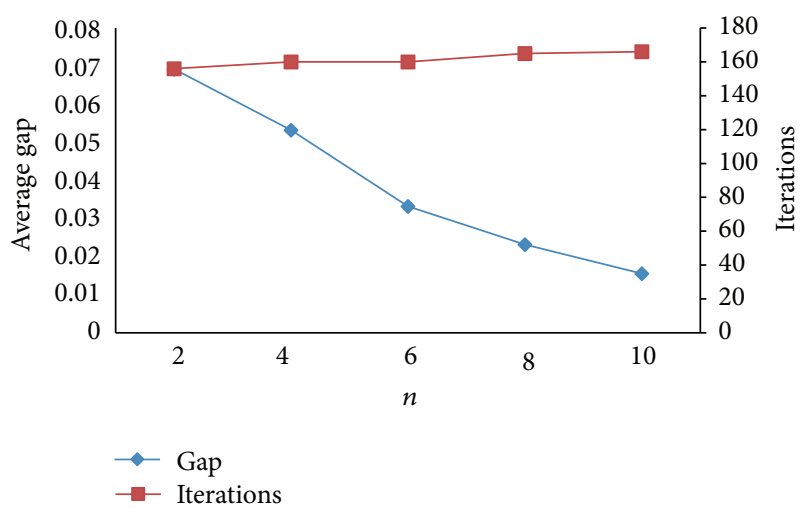

FIGURE 6: Sensitivity analysis of gaps of scenarios.

(iii) The measurement of social performance is completed based on Sustainability Reporting Guidelines (GRI), and four indicators are modeled.

(iv) The model is solved by AUGMENCON algorithm and verified by a constructed enterprise case study.

(v) The numerical experiment results show the integrating effect of all dimensions of sustainability. The set of trade-off solutions derived from AUGMENCON algorithm provides decision makers to make different decisions under different environment and social requirements.

Even though the sustainable logistics network modeling problem has been completely applied in this paper, there is still a lot to be done to break the limitations of this work. Future work should include some extensions such as considering the dynamic property of the network and the parameter uncertainty. For instance, the social performance is quantified as crisp in this paper, but it is always uncertain in the actual situation. The fuzzy theory such as fuzzy PROMETHEE approach that is proposed by Lolli et al. [39] could be a candidate for dealing with this kind of criteria. Regarding the solution approach, a multiobjective heuristic algorithm could be introduced to efficiently solve this kind of problem.

\section{Notations}

\section{Indices}

$i$ : Index of suppliers, $i \in I$

$j:$ Index of candidate locations for plants $j \in J$

$k$ : Index of customers, $k \in K$

$r:$ Index of raw materials, $r \in R$

$p$ : Index of products, $p \in P$

$t$ : Index of production technologies, $t \in T$

$m$ : Index of environmental impact categories, $m \in M$

$v$ : Index of vehicle types, $v \in V$

\section{Parameters}

$\mathrm{cf}_{j}$ : The fixed construction cost of the plant $j$, in yuan $\mathrm{cb}_{i}^{r}: \quad$ Procurement cost of supplier $i$ for raw material $r$, in yuan per item

$\mathrm{cp}_{j}^{t p}: \quad$ Production cost of plant $j$ with production technology $t$ to produce product $p$, in yuan per item

$\mathrm{ct}_{r}$ : $\quad$ Transportation cost for raw material $r$, in yuan per item per $\mathrm{km}$

$\mathrm{ct}_{p}: \quad$ Transportation cost for product $p$, in yuan per item per $\mathrm{km}$

$d_{i j}$ : $\quad$ Distance between plant $j$ and supplier $k$, in $\mathrm{km}$

$d_{j k}$ : Distance between supplier $i$ and plant $j$, in $\mathrm{km}$

$D_{k}^{p}$ : $\quad$ Demand of customer $k$ for product $p$, in item

$u_{p}^{r}: \quad$ Number of raw materials to produce one united product $p$, in item

cap $_{j}: \quad$ Capacity of plant $j$, in item

cap $_{v}: \quad$ Capacity of vehicle type $v$, in item

$\alpha_{i j}^{r v}: \quad$ Number of vehicles $v$ for transporting raw material $r$ from supplier $i$ to plant $j$

$\beta_{j k}^{p v}: \quad$ Number of vehicle $v$ for transport product $p$ from plant $j$ to customer $k$

$Q_{v}$ : $\quad$ Load capacity of vehicle $v$, in ton

$\operatorname{Nor} p_{m}^{p}$ : Normalization value of environment impact $m$ to produce product $p$

$\operatorname{Nor} v_{m}^{v}$ : Normalization value of environment impact $m$ in transportation by vehicle type $v$

$\mathrm{PI}_{m}$ : Total value of environment impact $m$ in production

$\mathrm{TI}_{m}$ : Total value of environment impact $m$ in transportation

$\mathrm{jc}_{j}$ : $\quad$ Number of jobs created when plant $j$ is open

up $_{j}$ : Unemployment rate of the region where plant $j$ is located

$\mathrm{vp}_{j}$ : Total economic value generated by products in plant $j$, in 10 thousand yuan

$\operatorname{edp}_{j}$ : Local development level (represented by GDP growth rate) of the region where plant $j$ is located

$\mathrm{ld}^{t}$ : Average annual lost days when technology $t$ is used, in days

$\operatorname{pr}^{t}: \quad$ Average percentage of risky products $t$ when technology $t$ is used

S: $\quad$ Social indicators, $S=\left\{S_{1}, S_{2}, S_{3}, S_{4}\right\}$

$S_{1}$ : $\quad$ Social indicator "employment", $S_{1}=\sum_{j \in J} \sum_{t \in T} \mathrm{jc}_{j} \operatorname{up}_{j} Y_{j}^{t}$

$S_{2}$ : $\quad$ Social indicator "local development", $S_{2}=\sum_{j \in J} \sum_{t \in T} \operatorname{vp}_{j}\left(1-\operatorname{edp}_{j}\right) Y_{j}^{t}$

$S_{3}$ : $\quad$ Social indicator "health and safety of employee", $S_{3}=\sum_{j \in J} \sum_{t \in T} \operatorname{ld}^{t} Y_{j}^{t}$

$S_{4}$ : $\quad$ Social indicator "customer risk", $S_{4}=\sum_{j \in J} \sum_{t \in T} \sum_{p \in P} \operatorname{pr}^{t} G_{j}^{t p}$

$\omega$ : Weight of different social indicators, $\omega=\left\{\omega_{1}, \omega_{2}, \omega_{3}, \omega_{4}\right\}$

Variables

$Y_{j}^{t}$ : Binary variable, $Y_{j}^{t}=1$ when plant $j$ with technology $t$ is open; otherwise, $Y_{j}^{t}=0$ 
$X_{i j}^{r}$ : Quantity of raw material $r$ provided by supplier $i$ and sent to plant $j$

$Z_{j k}^{p}$ : Quantity of product $p$ produced at plant $j$ and allocated to customer $k$

$G_{j}^{t p}$ : Quantity of product $p$ produced at plant $j$ with technology $t$.

\section{Competing Interests}

The authors declare that they have no competing interests.

\section{References}

[1] C. R. Carter and D. S. Rogers, "A framework of sustainable supply chain management: moving toward new theory," International Journal of Physical Distribution and Logistics Management, vol. 38, no. 5, pp. 360-387, 2008.

[2] P. Ahi and C. Searcy, "A stochastic approach for sustainability analysis under the green economics paradigm," Stochastic Environmental Research \& Risk Assessment, vol. 28, no. 7, pp. 17431753, 2014.

[3] D. Aksen and K. Altinkemer, "A location-routing problem for the conversion to the "click-and-mortar" retailing: the static case," European Journal of Operational Research, vol. 186, no. 2, pp. 554-575, 2008.

[4] Y. Hinojosa, J. Kalcsics, S. Nickel, J. Puerto, and S. Velten, "Dynamic supply chain design with inventory," Computers \& Operations Research, vol. 35, no. 2, pp. 373-391, 2008.

[5] P. A. Miranda and R. A. Garrido, "Valid inequalities for Lagrangian relaxation in an inventory location problem with stochastic capacity," Transportation Research Part E: Logistics and Transportation Review, vol. 44, no. 1, pp. 47-65, 2008.

[6] F. Wang, X. Lai, and N. Shi, "A multi-objective optimization for green supply chain network design," Decision Support Systems, vol. 51, no. 2, pp. 262-269, 2011.

[7] A. Chaabane, A. Ramudhin, and M. Paquet, "Design of sustainable supply chains under the emission trading scheme," International Journal of Production Economics, vol. 135, no. 1, pp. 37-49, 2012.

[8] M. S. Pishvaee, J. Razmi, and S. A. Torabi, "An accelerated Benders decomposition algorithm for sustainable supply chain network design under uncertainty: a case study of medical needle and syringe supply chain," Transportation Research Part E: Logistics \& Transportation Review, vol. 67, pp. 14-38, 2014.

[9] S. Cholette and K. Venkat, "The energy and carbon intensity of wine distribution: a study of logistical options for delivering wine to consumers," Journal of Cleaner Production, vol. 17, no. 16, pp. 1401-1413, 2009.

[10] J. B. Edwards, A. C. McKinnon, and S. L. Cullinane, "Comparative analysis of the carbon footprints of conventional and online retailing: a "last mile" perspective," International Journal of Physical Distribution \& Logistics Management, vol. 40, no. 1-2, pp. 103-123, 2010.

[11] F. Xiao, Z.-H. Hu, K.-X. Wang, and P.-H. Fu, "Spatial distribution of energy consumption and carbon emission of regional logistics," Sustainability, vol. 7, no. 7, pp. 9140-9159, 2015.

[12] S. N. Wang, "Low carbon supply chain network design with uncertain demand," Logistics Engineering and Management, vol. 7, pp. 177-179, 2014.

[13] A. Tognetti, P. T. Grosse-Ruyken, and S. M. Wagner, "Green supply chain network optimization and the trade-off between environmental and economic objectives," International Journal of Production Economics, vol. 170, no. 1, pp. 385-392, 2015.

[14] I. Ferretti, S. Zanoni, L. Zavanella, and A. Diana, "Greening the aluminium supply chain," International Journal of Production Economics, vol. 108, no. 1-2, pp. 236-245, 2007.

[15] M. Pizzol, P. Christensen, J. Schmidt, and M. Thomsen, "Ecotoxicological impact of 'metals' on the aquatic and terrestrial ecosystem: a comparison between eight different methodologies for Life Cycle Impact Assessment (LCIA)," Journal of Cleaner Production, vol. 19, no. 6-7, pp. 687-698, 2011.

[16] J. Guinée, "Handbook on life cycle assessment-operational guide to the ISO standards," International Journal of Life Cycle Assessment, vol. 6, no. 5, pp. 255-255, 2001.

[17] M. Goedkoop and R. Spriensma, "The Eco-indicator 99: a damage oriented method for life cycle impact assessment: methodology report," VROM Zoetermeer Nr 1999/36A/B, PRé Sustainability, Amersfoort, The Netherlands, 2000.

[18] M. Hauschild, "Spatial differentiation in life cycle impact assessment: a decade of method development to increase the environmental realism of LCIA," International Journal of Life Cycle Assessment, vol. 11, supplement 1, pp. 11-13, 2006.

[19] B. Steen, A Systematic Approach to Environmental Priority Strategies in Product Development (EPS).Version 2000-General System Characteristics, Chalmers University of Technology, 1999.

[20] O. Jolliet, M. Margni, R. Charles et al., "IMPACT 2002+: a new life cycle impact assessment methodology," The International Journal of Life Cycle Assessment, vol. 8, no. 6, pp. 324-330, 2003.

[21] E. Paul, Obstacles to democratization in Southeast Asia, Palgrave Macmillan UK, 2010.

[22] J. C. Bare, G. A. Norris, D. W. Pennington et al., "TRACI-the tool for the reduction and assessment of chemical and other environmental impacts," Environmental Microbiology, vol. 8, no. 6, 2003.

[23] M. Goedkoop, R. Heijungs, M. Huijbregts et al., "ReCiPe 2008," Minds \& Machines, vol. 4, pp. 595-599, 2009.

[24] ISO, Final Draft International Standard ISO/FDIS 26000:2010, Guidance on Social Responsibility, International Organization for Standardization, Geneva, Switzerland, 2010.

[25] SAI, Social Accountability 8000 (SA8000), SAI, New York, NY, USA, 2008.

[26] ETI, The Base Code, [EB/OL], 2009, http://www.ethicaltrade .org/resources/key-eti-resources/eti-base-code.

[27] FLA, Workplace Code of Conduct, [EB/OL], 2011, http://www fairlabor.org.

[28] UNGC, "An Inspironal Guid to Implementing the Global Compact [EB/OL]," http://www.unglobalcompact.org/.

[29] C. Benoît, G. A. Norris, S. Valdivia et al., "The guidelines for social life cycle assessment of products: just in time!”, International Journal of Life Cycle Assessment, vol. 15, no. 2, pp. 156$163,2010$.

[30] GRI, Sustinability Reporting Guidelines, Version 3.1, 2011.

[31] S. G. Tayyar, D. Roy, and S. F. Ghaderi, "Economic, environmental and social responsible supply chain design using differential evolution multi objective algorithm," in Proceedings of the IEEE International Conference on Industrial Engineering and Engineering Management (IEEM '13), pp. 1617-1621, IEEE, Bangkok, Thailand, December 2013.

[32] Z. Chen and S. Andresen, "A multiobjective optimization model of production-sourcing for sustainable supply chain with 
consideration of social, environmental, and economic factors," Mathematical Problems in Engineering, vol. 2014, Article ID 616107, 11 pages, 2014.

[33] L. Xu and Y. Q. Teng, "Sustainable supply chain network design based on social responsibility," Logistics Technology, vol. 34, no. 21, 2015 .

[34] R. Gamberini, E. Gebennini, A. Grassi, C. Mora, and B. Rimini, "An innovative model for WEEE recovery network management in accordance with the EU directives," International Journal of Environmental Technology and Management, vol. 8, no. 4, pp. 348-368, 2008.

[35] R. Gamberini, E. Gebennini, and B. Rimini, "An innovative container for WEEE collection and transport: details and effects following the adoption," Waste Management, vol. 29, no. 11, pp. 2846-2858, 2009.

[36] R. Gamberini, D. Del Buono, F. Lolli, and B. Rimini, "Municipal solid waste management: identification and analysis of engineering indexes representing demand and costs generated in virtuous Italian communities," Waste Management, vol. 33, no. 11, pp. 2532-2540, 2013.

[37] R. Gamberini, B. Rimini, and P. Nicandri, "Composting of municipal solid waste: an empirical analysis of existing plants," Transactions of the ASABE, vol. 56, no. 5, pp. 1887-1893, 2013.

[38] S. Seuring, "A review of modeling approaches for sustainable supply chain management," Decision Support Systems, vol. 54, no. 4, pp. 1513-1520, 2013.

[39] F. Lolli, A. Ishizaka, R. Gamberini et al., "Waste treatment: an environmental, economic and social analysis with a new group fuzzy PROMETHEE approach," Clean Technologies and Environmental Policy, vol. 18, no. 5, pp. 1317-1332, 2016.

[40] Y. Yang, B. Zhang, and L. Meng, "Closed-loop supply chainmulti-crieria decision equilibrium problem with environmental consideration," Journal of System Managenet, vol. 23, no. 1, pp. 13-20, 2014.

[41] M. N. Faisal, "Sustainable supply chains: a study of interaction among the enablers," Business Process Management Journal, vol. 16, no. 3, pp. 508-529, 2010.

[42] C. Bai and J. Sarkis, "Green supplier development: analytical evaluation using rough set theory," Journal of Cleaner Production, vol. 18, no. 12, pp. 1200-1210, 2010.

[43] OECD, "Pursuing Strong, Sustainable and Balanced Grouth: The role of structrual Reform [EB/OL]," http://www.oecdchina .org/.

[44] F. Dehghanian and S. Mansour, "Designing sustainable recovery network of end-of-life products using genetic algorithm," Resources, Conservation \& Recycling, vol. 53, no. 10, pp. 559-570, 2009.

[45] D. Krajnc and P. Glavič, "Indicators of sustainable production," Clean Technologies and Environmental Policy, vol. 5, no. 3, pp. 279-288, 2003.

[46] K. Malik, "Human development report 2013. The rise of the south: human progress in a diverse world," Afrique Contemporaine, vol. 39, no. 3, pp. 548-549, 2013.

[47] B. Chandran, B. Golden, and E. Wasil, "Linear programming models for estimating weights in the analytic hierarchy process," Computers \& Operations Research, vol. 32, no. 9, pp. 2235-2254, 2005.

[48] G. Mavrotas, "Effective implementation of the $\varepsilon$-constraint method in Multi-Objective Mathematical Programming problems," Applied Mathematics \& Computation, vol. 213, no. 2, pp. 455-465, 2009.
[49] M. Ehrgott and M. M. Wiecek, "Mutiobjective Programming," 2005. 


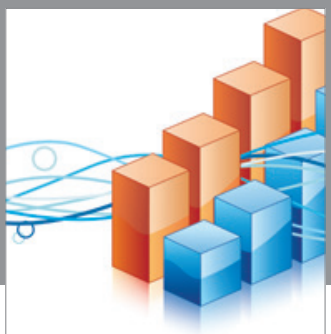

Advances in

Operations Research

vatem alat4

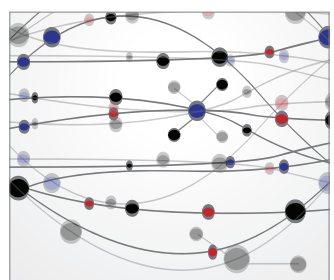

\section{The Scientific} World Journal
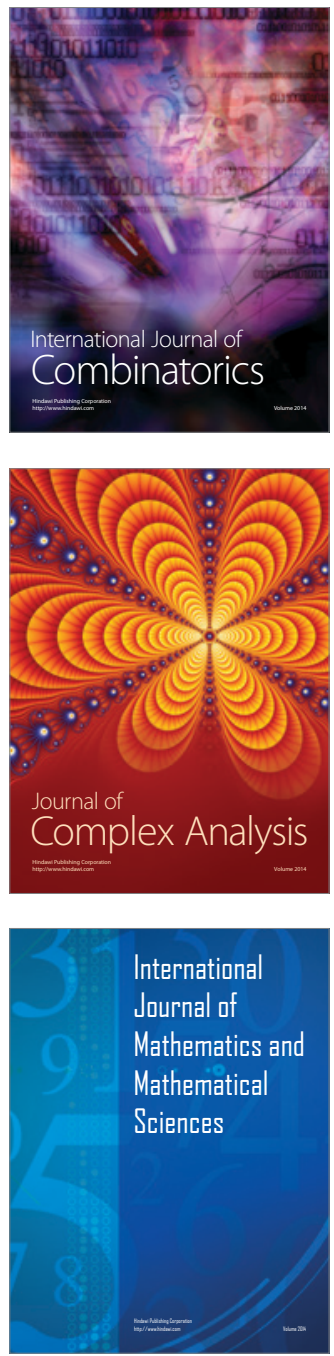
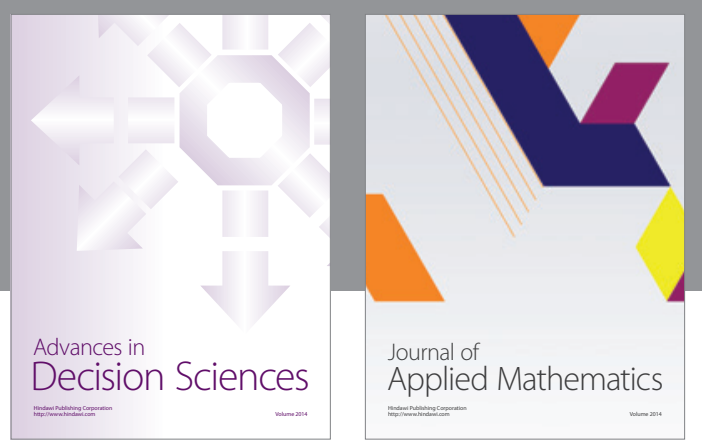

Algebra

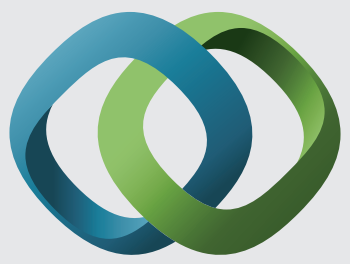

\section{Hindawi}

Submit your manuscripts at

https://www.hindawi.com
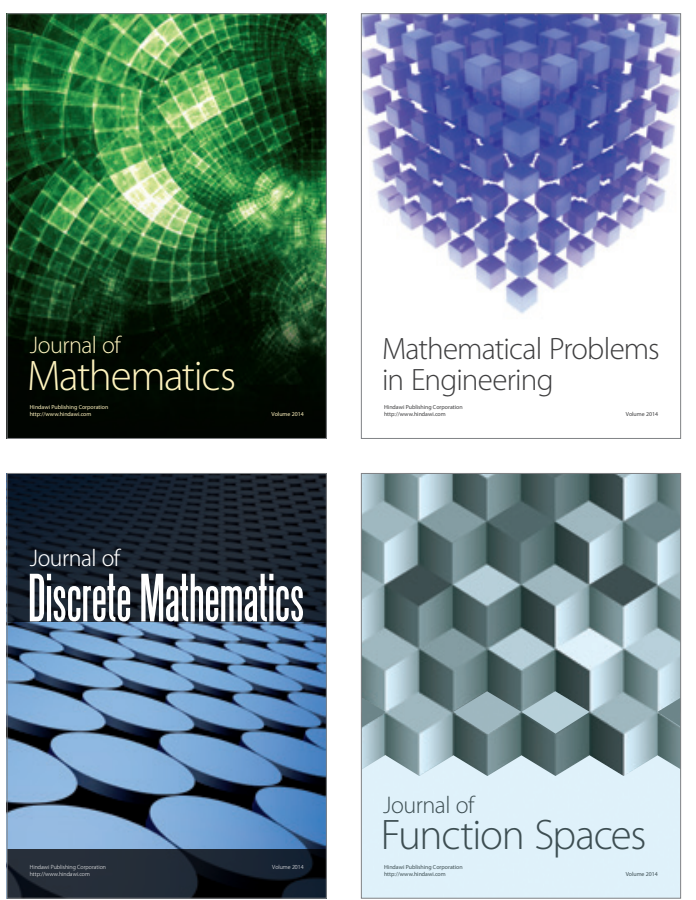

Mathematical Problems in Engineering
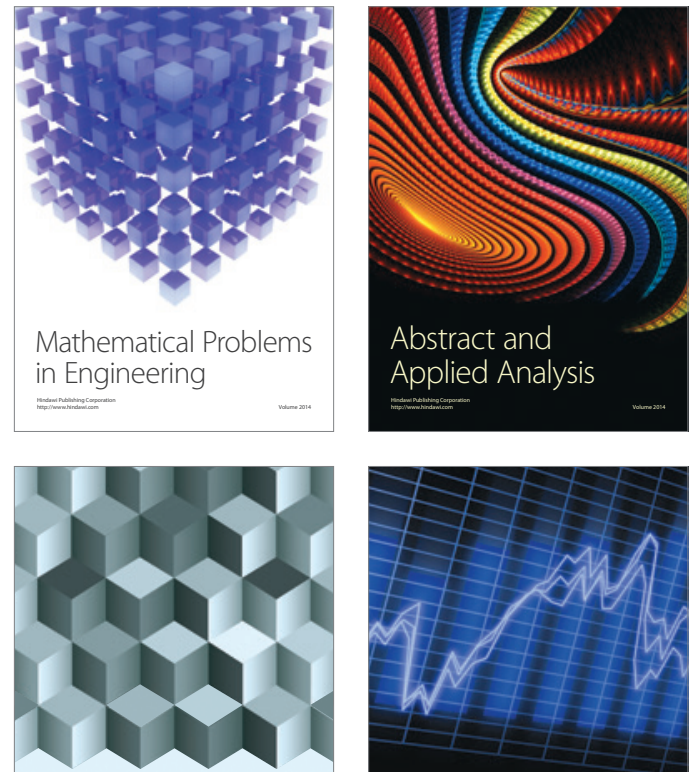

Journal of

Function Spaces

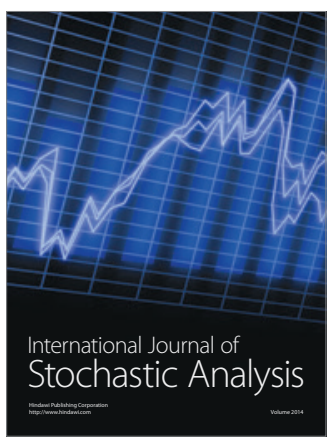

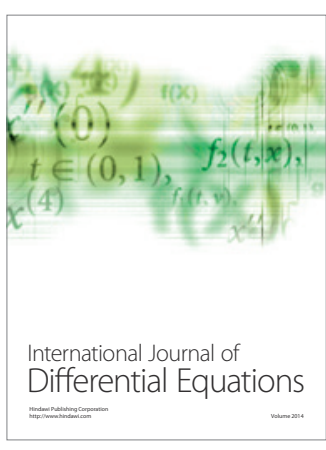
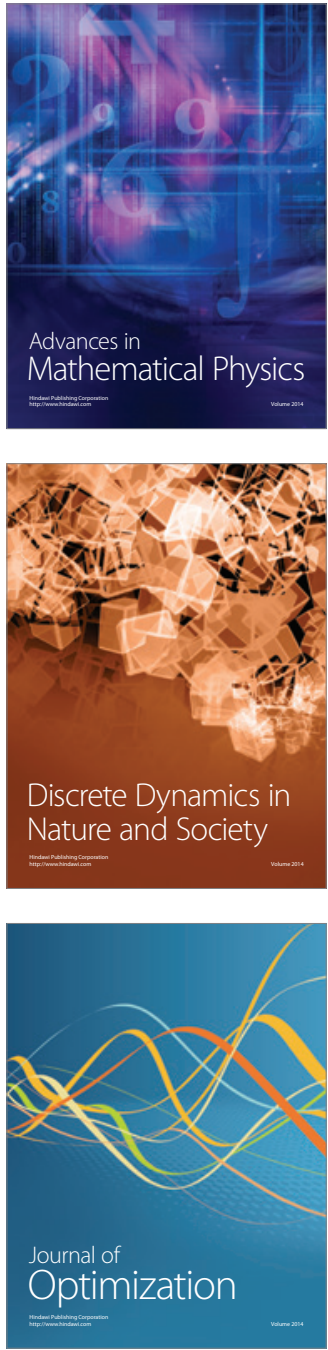